\title{
BREVE ANÁLISE SOBRE O INSTITUTO DESAPOSENTAÇÃO: DIREITO ADQUIRIDO OU FATOR AGRAVANTE DA CRISE DO SISTEMA PREVIDENCIÁRIO BRASILEIRO?
}

\author{
${ }^{1}$ Fernanda Heloisa Macedo Soares
}

\section{RESUMO}

O instituto desaposentação tem sido tema de grande polêmica no âmbito do Direito Previdenciário, pois apesar de não ser prevista pelo ordenamento jurídico brasileiro, logo não pode ser admitida de forma administrativa, porém o Poder Judiciário compreende sua incidência. Diante disso, o presente trabalho tem como objetivo analisar se a desaposentação é direito adquirido do trabalhador que mesmo após sua aposentadoria continua contribuindo e assim pretende ter seu benefício atualizado ou ao se acatar tal possibilidade se tornará mais um fator agravante da crise do sistema previdenciário brasileiro.

Palavras-chave: Desaposentação. Previdência Social. Seguridade Social. Aposentadoria.

\section{BRIEF ANALYSIS OF THE DESAPOSENTAÇÃO INSTITUTE: RIGHT ACQUIRED OR AGGRAVATING FACTOR OF SYSTEM CRISIS BRAZILIAN SOCIAL SECURUTY?}

\begin{abstract}
The desaposentação institute has been the subject of great controversy in the Social Security Law, because despite not being provided by the Brazilian Legal System, and therefore can not be accepted administratively, but the judiciary its implications. Thus, this study aims to analyze if the desaposentção is acquired right of the worker after his retirement continues to contribute an so you want to have your updated benefit or to accept such a possibility will become an aggravating factor of the Brazilian Social Security system crisis.
\end{abstract}

Keywords: Disappointing. Social Security. Social Security. Retirement

\footnotetext{
1 Mestre em Direito, área de concentração Teoria do Direito e do Estado, pelo Centro Universitário Eurípides de Marília UNIVEM - São Paulo, (Brasil). Advogada e Professora Universitária. Atua como docente na Faculdade Evangélica de Goianésia (FACEG). E-mail: haja_fer@uol.com.br
} 


\section{INTRODUÇÃO}

A crise vivenciada pela previdência social é um fato alarmante que preocupa a sociedade brasileira. Com efeito, é a previdência social que assegura alguns direitos, exteriorizados em forma de benefícios, como, por exemplo, a aposentadoria, cujos destinatários são os trabalhadores, e, a sua crise provoca insegurança aos contribuintes que participam desse sistema. Diante disso, muito tem sido debatido sobre a previdência social, de forma que o instituto da desaposentação é objeto não apenas de grande polêmica, mas também, com divergências entre a esfera administrativa e o âmbito judicial. Isso significa que existem opiniões e argumentos de ambos os lados quanto à aplicabilidade do Direito e que, portanto, devem ser analisados a fim de que se compreenda com clareza o significado da ideia de desaposentação.

Portanto, o instituto da desaposentação se apresenta como um instituto que carece de estudos e pesquisas a fim de que tanto a comunidade jurídica como a sociedade em geral possa compreender claramente o mesmo. Nesse cenário, o presente estudo científico trata da desaposentação, incluindo as questões normativas, o posicionamento jurisprudencial e a análise dos argumentos favoráveis e contra a aplicação desse instituto. Em assim sendo, busca-se responder a seguinte indagação: a desaposentação deve ser vista como um direito ou mais um fator agravante da crise do sistema previdenciário brasileiro?

O objetivo geral da pesquisa é analisar o instituto da desaposentação a fim de definir quais as perspectivas jurídicas brasileiras sobre o mesmo. Os objetivos específicos são: contextualizar a seguridade social nos moldes em que se apresenta no Estado brasileiro, sobretudo, à luz da Constituição Federal de 1988 e seus princípios; examinar a previdência social, a fim de esclarecer as suas características e seus benefícios, de forma geral, tidos como direitos sociais; definir o que é a desaposentação, de modo a demonstrar se esse instituto pode ser considerado como um direito ou como um fator agravante da crise do sistema previdenciário brasileiro.

\section{SEGURIDADE SOCIAL: ASPECTOS HISTÓRICOS E PERSPECTIVAS NA CONSTITUIÇÃO FEDERAL}

Ao se tratar de seguridade social é inevitável que se faça uma relação com a nossa Constituição, visto que ao ser considerada como a Constituição Cidadã possui forte enfoque 
social, advindo dos anos de cerceamento de direitos e garantias fundamentais que a antecederam.

A Constituição da República Federativa do Brasil, de 05 de outubro de 1988, em seu Título VIII, Capítulo II, dispõe sobre a seguridade social. Não obstante, o art. 193, desse documento normativo, determina que "A ordem social tem como base o primado do trabalho, e como objetivo o bem-estar e a justiça sociais". Logo, percebe-se que a norma constitucional vigente no Estado brasileiro preza pelo bem-estar e pela justiça social.

Observa-se que a Constituição da República Federativa do Brasil compreendida como sendo composta por diversos dispositivos que buscam resguardar os valores sociais do trabalho, em consonância com o regime democrático. Isso significa que a Letra Fundamental vigente atribui relevância ao bem-estar, à justiça social e à existência digna de todos os trabalhadores, inclusive, esses pressupostos devem ser não apenas considerados, mas assegurados pela ordem econômica.

Nesse sentido, Carvalho (2012, p. 1343) assevera que "o capital constitui, pois, instrumento para a promoção do bem-estar dos indivíduos, e não um fim em si mesmo". Com efeito, os ganhos financeiros e o crescimento econômico são essenciais para o desenvolvimento do país, contudo, os meios utilizados devem ser revestidos de características que valorizem a pessoa humana, assegurando a dignidade e o bem-estar dos indivíduos.

A ordem social, que engloba a seguridade social na Constituição Federal de 1988, é considerada por Araujo e Nunes Júnior (2014, p. 580) da seguinte forma:

\begin{abstract}
A Constituição brasileira de 1988, seguindo a tradição de nossas Constituições, tratou de disciplinar regras relativas à ordem social. Sua disciplina minuciosa é retrato do grau de desconfiança dos constituintes nas instituições, mostrando uma minúcia poucas vezes vista em um texto constitucional. Aliás, tal característico permeia todo o texto, estando, portanto, acentuado no disciplinar relações as mais específicas e cuidando com pormenor de questões que, à primeira vista, poderiam estar fora do texto constitucional. [...] Essa opção do constituinte deu origem ao que denominamos Constituição Social, ou seja, o conjunto de normas constantes da Constituição predispostas à regração da ordem social, entendida de maneira abranger os setores onde o Estado devia intervir por meio de prestações sociais, seja indicando direitos aos indivíduos (seguridade Social), seja intervindo na realidade para propiciar um sistema de relações sociais mais equilibrado e justo.
\end{abstract}

Pode-se perceber que a Constituição Federal de 1988 é tida como uma Constituição Social, pois em sua laboração, o legislador constituinte, preocupado com a efetividade dos preceitos da ordem social, adotou um texto minucioso e detalhista, incluindo questões que poderiam ser tratadas no plano infraconstitucional. Por conseguinte, há previsões constitucionais 
no âmbito da ordem social que se dirigem à estabelecer ações positivas por parte do Estado, seja prevendo e proporcionando a materialização de direitos individuais, ou ainda, intervindo em situações reais e específicas, a fim de garantir equilíbrio nas relações sociais.

Bonavides (2013, p. 390) esclarece sobre a questão em comento:

\begin{abstract}
O Estado social é enfim Estado produtor de igualdade fática. Trata-se de um conceito que deve iluminar sempre toda a hermenêutica constitucional, em se tratando de estabelecer equivalência de direitos. Obriga o Estado, se for o caso, a prestações positivas; a prover meios, se necessário, para concretizar comandos normativos de isonomia. Noutro lugar já escrevemos que a isonomia fática é o grau mais alto e talvez mais justo e refinado a que se pode subir o princípio da igualdade numa estrutura normativa de direito positivo.
\end{abstract}

Depreende-se ao enfatizar a órbita social, a Constituição Federal de 1988 impõe ao Estado o dever de assegurar direitos, por meio de prestações positivas e a promoção de maneiras, que sejam suficientes para materializar a ideia de isonomia. Na esfera social isso significa que o Estado deve assegurar aos seus membros a possibilidade de exercer os direitos estabelecidos, garantindo o bem-estar de todos e, inclusive, condições de desenvolvimento.

Se por um lado há direitos que afastam a intervenção estatal, assegurando as liberdades individuais, os denominados direitos de defesa ou de primeira geração, por outro lado, os direitos sociais ensejam a atuação positiva e fática do Estado. Dentre os direitos sociais encontramse os direitos relativos à previdência social, que englobam a seguridade social.

Em assim sendo, Farineli (2013, p. 38) apresenta o seguinte entendimento sobre a seguridade social:

\footnotetext{
A Seguridade Social engloba um conceito amplo, abrangente, universal, determinado a todos que dela necessitem, desde que haja previsão na lei determinado evento a ser coberto. É, na verdade, o gênero do qual são espécies a Previdência Social, a Assistência Social e a Saúde.
}

A seguridade social, portanto, abrange uma série de direitos e serviços previstos em lei que a mesma deve proporcionar a todas as pessoas que lhe requisitem, havendo previsão legal sobre os eventos a serem cobertos. Para tanto, a seguridade social comporta a previdência social, a saúde e a assistência social. 
A previdência social é considerada por Vieira (2004, p. 21) como um dos subgrupos da seguridade social, que compreende, ainda, a assistência social e a saúde. Dessa forma, cumpre salientar as seguintes lições de Ibrahim (2003, p. 06):

\begin{abstract}
A seguridade social pode ser conceituada como a rede protetiva formada pelo Estado e por particulares, com contribuições de todos, incluindo parte dos beneficiários dos direitos, no sentido de estabelecer ações positivas no sustento de pessoas carentes, trabalhadores em geral e seus dependentes, providenciando a manutenção de um padrão mínimo de vida. A intervenção estatal, na composição da seguridade social, é obrigatória, por meio da ação direta ou controle, a qual deve atender a toda e qualquer demanda referente ao bem-estar da pessoa humana.
\end{abstract}

Assim, a seguridade social pode ser considerada como o sistema protetivo que enseja a participação tanto dos particulares como do Estado. No que se refere à participação dos particulares, essa se verifica com a realização da contribuição de todos, os quais serão beneficiários do sistema, bem como outros, os quais são considerados carentes e necessitam de ações positivas para assegurar o próprio sustento. Quanto ao Estado, a sua participação é imprescindível e pode ser apontada por ações direta ou de controle do sistema, de modo a assegurar que todos aqueles que precisam serão atendidos.

Não obstante, destaca-se o entendimento demonstrado de Ibrahim (2003) no que se refere ao bem-estar da pessoa humana e a seguridade social. Tal juízo compreende que o bem- estar da pessoa humana é razão para justificar a intervenção estatal no âmbito da seguridade social, pois, cabe ao Estado assegurar os direitos de seus membros.

Carvalho (2012, p. 1344-1345) ressalta que a seguridade social, como se encontra nos moldes atuais, passou da assistência com caráter de caridade, por meio de atividades religiosas, para só posteriormente ser realizada por instituições propriamente públicas. O autor remete essa mudança à Inglaterra, no ano de 1601, com o surgimento da assistência pública e social e acrescenta:

E da assistência pública passa-se à fase do seguro social, em virtude da questão social e das conquistas da revolução Francesa, tem sido a primeira forma de seguro, de que se tem notícia, o seguro marítimo, que surgiu em decorrência das reivindicações dos comerciantes italianos. [...] O seguro voluntário, contratual, não logrou garantir proteção social à classe trabalhadora, pois se destina apenas à minoria que podia custeá-lo, deixando ao desabrigo os mais necessitados. Nasce, então, no final do século XIX, o seguro social, que inaugurou a etapa de proteção dos trabalhadores. Nada obstante ter como modelo o do seguro privado, de cuja relação participavam empregador, empregado e Estado, a este se passou a incumbência de recolher e administrar os recursos para financiamento. O primeiro plano de previdência social, de que se tem notícia, foi o de Bismarck, na Prússia, em

1883, que, pela Lei do Seguro-Doença, criou o seguro-enfermidade, iniciando-se aí uma nova conceituação de proteção social, com o fortalecimento do seguro e sua extensão a 
cobertura de riscos de doença, acidente, invalidez, velhice, viuvez, orfandade, desemprego.

A seguridade social passou por mudanças de perspectivas ao longo dos tempos, indo da ideia de caridade, realizada pela Igreja, ao seguro social. Observa-se que a Revolução Francesa teve impactos que geraram inovações por parte dos trabalhadores, que a época reivindicavam direitos e a proteção estatal. Além disso, percebe-se que o seguro social, antes voluntário, não refletiu resultados efetivos, pois, acabava limitando os que dele conseguiam participar, ficando então desamparados os mais necessitados. Destarte, surgiu então o seguro obrigatório, com a participação dos trabalhadores, empregadores e Estado no sistema, de modo que ao Estado foi incumbido o dever de recolher e administrar os recursos envolvidos.

Castro e Lazzari (2010, p. 49-50) explana sobre o seguro social:

\begin{abstract}
Com efeito, o seguro social, imposto por normas jurídicas emanadas do poder estatal, caracteriza uma intervenção do Estado na economia e na relação entre particulares. E não é outra a função do poder estatal, senão a de assegurar o bem comum da sociedade a que serve. A ação estatal se justifica a partir da constatação de que as relações de trabalho estabelecem, em regra, cláusulas para vigorarem enquanto o trabalhador as pode executar. A ausência de previsão para a hipótese de impossibilidade de execução dos serviços pelo obreiro, em face de sua incapacidade laborativa temporária ou permanente -, acarreta a este a possibilidade, sempre presente, de vir a ser colocado à margem da sociedade, como um ser não-útil, e, por esta razão, ignorado pelos detentores dos meios de produção, sem direito a qualquer retribuição por parte daquele que empregava a sua mão-de-obra. Nesse sentido, impõe-se afirmar que concordamos seja necessária a intervenção estatal, uma vez que, conforme a própria doutrina internacional preconiza, o Estado utiliza a regulamentação e a prestação de serviços no campo previdenciário [...] a fim de garantir um regime que trate isonomicamente a todos os trabalhadores - garantia esta não concedida por um regime de previdência puramente privada -, permitindo o acesso universal aos benefícios previdenciários.
\end{abstract}

Entende-se que a seguridade social, que compreende a previdência social, é o meio pelo qual o Estado assegura a todos condições de sobrevivência, quando os indivíduos se encontrarem em situações que lhe impedem assegurar o próprio sustento e o de seus dependentes. Desse modo, por meio de disposições legais, o sistema é organizado, determinando quais os benefícios que são oferecidos e em quais situações podem ser concedidos, em consonância com a ordem internacional.

Nesse contexto, Silva (2013, p. 840) afirma que "os benefícios previdenciários são prestações pecuniárias aos segurados e a qualquer pessoa que contribua para a previdência social na forma dos planos previdenciários". Isso significa que todas as pessoas que contribuam com o sistema, trabalhadores ou não, terão direito a acesso aos benefícios previdenciários, de acordo com o respectivo plano adotado, o que ocorre por meio de prestações pecuniárias. 
Cumpre destacar que a assistência social, compreendida na seguridade social, "é um direito assegurado pela Constituição a quem dela necessitar, independentemente de contribuição à seguridade social”, conforme assevera Carvalho (2012, p. 1351). O autor ainda denota às disposições do art. 203, da Constituição Federal, de 1988, que estabelece como objetivos da assistência social "a proteção à família, à maternidade, à infância, à adolescência e à velhice”; “o amparo às crianças e adolescentes carentes"; "a promoção da integração ao mercado de trabalho"; “a habilitação e reabilitação das pessoas portadoras de deficiência e a promoção de sua integração à vida comunitária"; e a "garantia de um salário mínimo de benefício mensal à pessoa portadora de deficiência e ao idoso que comprovem não possuir meios de prover à própria manutenção ou de tê-la provida por sua família, conforme dispuser

a lei”

Pelo exposto, pode-se dizer que a seguridade social compreende um sistema que busca a efetivação dos direitos sociais nos âmbitos previdenciário, assistencial e da saúde. Com a participação da sociedade e do Estado, objetiva-se assegurar o bem-estar dos indivíduos e a justiça social, por meio de um atendimento igualitário. Considerando que a seguridade social comporta a previdência social, a assistência social e a saúde, tem-se que a primeira oferece benefícios aos indivíduos que participam do seu financiamento, através de suas contribuições. Já a assistência social e a saúde não exigem contribuição do indivíduo para acesso aos serviços oferecidos, ou seja, é de acesso universal.

Entretanto, cumpre analisar de forma mais detalhada a previdência social, incluindo os seus princípios estabelecidos constitucionalmente.

\section{PREVIDÊNCIA SOCIAL: PRINCÍPIOS CONSTITUCIONAIS NORTEADORES DO SISTEMA BRASILEIRO}

Visto que a seguridade social se compõe da previdência social, da assistência social e da saúde, esta parte da pesquisa se volta para o esclarecimento sobre a previdência social, especialmente sobre os seus princípios norteadores, conforme as disposições inerentes à Constituição Federal de 1988.

O caput do art. 201, da Constituição Federal, estabelece: "a previdência social será organizada sob a forma de regime geral, de caráter contributivo e de filiação obrigatória, observados critérios que preservem o equilíbrio financeiro e atuarial", de forma a atender benefícios previstos em lei. Logo, tem-se que a previdência social, como um dos seguimentos da 
seguridade social, cuida de um sistema de participação obrigatória e caráter contributivo, considerando aspectos de equilíbrio financeiro e atuarial.

Vianna (2008, p. 53) tece as seguintes considerações sobre a previdência social:

\begin{abstract}
Organizada sob a forma de regime geral, de caráter contributivo e de filiação obrigatória, a Previdência Social observa critérios que lhe preservem o equilíbrio financeiro e atuarial. O sistema previdenciário constitui-se em um direito protetivo, garantindo a seus segurados contribuintes meios de subsistência quando de períodos de improdutividade financeira, tais como doença, maternidade, idade avançada e invalidez. Abrange somente uma parcela da sociedade (em razão de seu caráter contributivo, a Previdência Social deixa à margem de seus benefícios aqueles que não exercem atividade remunerada (contribuintes obrigatórios) ou que manifestamente não expressam seu desejo associativo (contribuintes facultativos). A população mais carente, portanto, não contribuinte, usufrui apenas das ações da Saúde e das ações e benefícios mantidos pela Assistência Social.
\end{abstract}

A partir dessas colocações, é possível compreender que a previdência social se consubstancia num sistema que visa proteger seus segurados em momentos de contingência financeira. Desse modo, exige-se que, para usufruir dos benefícios disponibilizados pela previdência social, o propenso beneficiário seja contribuinte, que por sinal, é de filiação obrigatória aos que exercem atividade remunerada. Abarca, ainda, aqueles que, apesar de não exercerem essas atividades, decidem por aderir ao sistema voluntariamente, ou seja, os contribuintes facultativos. Por conseguinte, quem não contribui com a previdência social não pode usufruir seus benefícios, podendo se valer apenas dos demais seguimentos da seguridade social: saúde e assistência social.

Hovarth Júnior (2011, p. 10), por sua vez, apresenta a seguinte concepção de previdência social:

\begin{abstract}
A previdência social e um serviço público de tipo novo destinado a amparar a população economicamente ativa (segurados obrigatórios) ou não (segurados facultativos), que se encontra em situações de riscos ou contingencias sociais previstas em lei, essencialmente com benefícios e serviços, mediante a adoção da formula tripartite de custeio (Estado, empregadores, trabalhadores e/ou facultativos). Previdência social e o seguro social que substitui a renda do segurado ou segurada contribuinte quando perde sua capacidade de trabalho por motivo de doença, acidente de trabalho, velhice, maternidade, morte ou reclusão.
\end{abstract}

Segundo a perspectiva desse conceito, a previdência social se consubstancia em um serviço público, o qual é mantido pelo Estado, empregadores, trabalhadores e/ou facultativos, a fim se assegurar aos seus filiados, em situações de riscos ou contingências sociais, por meio de benefícios e serviços. Isso significa que a previdência social é uma espécie de seguro que vem a substituir a renda do segurado quando o mesmo não estiver em condições de trabalho. 
Dias e Macêdo (2010) explica que nesses momentos de contingências sociais, nas quais o trabalhador não consegue auferir renda, há repercussão negativa também em parcela da sociedade, como por exemplo, sua família que consequentemente será submetida a um estado de necessidade. Logo, quando a previdência social é acionada para atuar frente às contingências sociais que disponibiliza cobertura, há uma repercussão social.

É nesse cenário que se inserem os princípios da compulsoriedade e da contributividade, segundo Kertzman (2015, p. 33), que elucida sobre esses princípios: 


\begin{abstract}
O princípio da compulsoriedade é o que obriga a filiação a regime de previdência social aos trabalhadores que trabalhem. Se os segurados pudessem optar entre verter parte de sua remuneração para o sistema de previdência social ou utilizar todos os ganhos para pagamento das despesas domésticas, certamente a maioria escolheria a segunda alternativa. Diversos trabalhadores ficariam, portanto, excluídos do sistema protetivo, gerando um completo caos social, pois, quando ficassem impossibilitados de exercer suas atividades, não teriam como prover o seu sustento. A contributividade significa que, para ter direito a qualquer benefício da previdência social, é necessário enquadrar-se na condição de segurado, devendo contribuir para manutenção do sistema previdenciário. Até mesmo o aposentado que volta a exercer atividade profissional remunerada, é obrigado a contribuir para o sistema.
\end{abstract}

A análise desses dois princípios, compulsoriedade e contributividade reflete no entendimento de que esses princípios se complementam. Isso porque, o financiamento do sistema previdenciário depende da contribuição dos assegurados, contudo, sem o caráter compulsório dessa contribuição, muitos dos trabalhadores não iriam participar. Por certo, essa parcela dos trabalhadores que se negaria a contribuir com a previdência, caso não fosse compulsório, seria excluída do sistema do sistema protetivo, de forma que nos momentos de contingência não poderia usufruir dos respectivos benefícios.

Nesse sentido, Martinez (2014) fala em solidariedade forçada, na qual a participação de maioria contemporânea contribuindo com a previdência social é em favor da minoria hodierna, ou seja, inativa e da futura, os aposentados. Entretanto, o financiamento do sistema ainda conta com a participação do Estado e também dos empregadores.

Vianna (2008, p. 53) aponta como princípios e diretrizes específicos da previdência social a "universalidade de participação nos planos previdenciários, mediante contribuição"; "valor da renda mensal dos benefícios, substituídos do salário-de-contribuição ou do rendimento do trabalho do segurado, não inferior ao do salário mínimo"; "cálculo dos benefícios considerando-se os salários-de-contribuição corrigidos monetariamente"; e a "irredutibilidade do valor dos benefícios, de forma que lhe preserve o poder aquisitivo".

Acerca do princípio da universalidade de participação nos planos previdenciários, mediante contribuição, Ibrahim (2015, p. 66-67), lembrando que o mesmo se insere, quanto à previdência social, somente os contribuintes filiados, discorre:

Esse princípio possui dimensões objetiva e subjetiva, sendo a primeira voltada a alcançar todos os riscos sociais que possam gerar o estado de necessidade (universalidade de cobertura), enquanto a segunda busca tutelar toda a pessoa pertencente ao sistema protetivo (universalidade de atendimento). A universalidade de cobertura e atendimento é inerente a um sistema de seguridade social, já que este visa ao atendimento de todas as demandas sociais na área securitária. Além disso, toda a sociedade deve ser protegida, sem nenhuma parcela excluída. Obviamente, esse princípio é realizável, na medida em que recursos financeiros suficientes são obtidos. Não há como se criarem diversas 
prestações sem custeio respectivo. A universalidade será atingida dentro das possibilidades do sistema. [...] Assim funcionam os princípios, como o da universalidade de cobertura e atendimento, que 
é limitado por outros, como o da preexistência do custeio em relação ao benefício ou serviço. A resultante será sempre uma diretriz conciliadora, respeitando ambas as determinações, ainda que isto venha a limitar o alcance dos princípios envolvidos.

De acordo com esse autor, o princípio da universalidade de participação nos planos previdenciários, mediante contribuição, possui dois aspectos: por um lado, deve assegurar atendimento em todos os momentos de contingência social dos segurados pelo sistema; por outro lado, os segurados são limitados àqueles que participam ao sistema protetivo, ou seja, os contribuintes. Entretanto, ressalta-se que o princípio em análise deve ser aplicado não isoladamente, mas sim, com a interação com os demais. Diante disso, por exemplo, a universalidade de cobertura e atendimento se dá na medida em que ocorre a preexistência do custeio em relação ao benefício ou serviço.

Nesse sentido, Farineli (2013, p. 42) denota ao princípio da uniformidade e equivalência dos benefícios e serviços às populações urbanas e rurais, que significa que as mesmas contingências sociais serão cobertas tanto para os trabalhadores urbanos como aos trabalhadores rurais, e, em mesmo valor econômico. O mesmo autor adverte que tal princípio coaduna com o previsto no art. $7^{\circ}$, da Constituição Federal de 1988, que assegura direitos idênticos aos trabalhadores urbanos e rurais.

No que tange ao princípio do cálculo dos benefícios considerando-se os salários-decontribuição corrigidos monetariamente, Hovarth Júnior (2011, p. 23) o nomeia como princípio da irredutibilidade no valor dos benefícios, e explica:

\begin{abstract}
A irredutibilidade tem por objetivo a manutenção do poder real de compra, resguardando os benefícios da corrosão causada pela inflação. Ressalte-se que os benefícios previdenciários não estão atrelados ao salário-mínimo em virtude das regras adotadas pelo atual sistema previdenciário. A Constituição Federal assegura que os benefícios sofrerão reajuste periódico que preserve o valor real ou o poder de compra do beneficio. A periodicidade e os critérios de reajustamento são aspectos que devem ser estabelecidos pelas normas infraconstitucionais. [...] Enfim, e um princípio que visa garantir ao contribuinte e dependentes a irredutibilidade do valor do beneficio, o que significa a manutenção do poder real de compra.
\end{abstract}

Denota-se que princípio da irredutibilidade no valor dos benefícios visa garantir que ao dispor determinado benefício, o sistema irá proporcionar ao segurado o equivalente à proporção de suas contribuições. Isso impede que os benefícios sejam vinculados ao valor do salário mínimo, como também assegurar a manutenção do poder real de compra em face de desvalorização do dinheiro pela inflação.

Vianna (2008, p. 50) acrescenta que o princípio da irredutibilidade no valor dos benefícios inclui a ideia de que o benefício "não sofrerá qualquer redução de valor e não poderá 
ser objeto de desconto (salvo determinação legal ou judicial), arresto, sequestro ou penhora". Isto é, o princípio da irredutibilidade no valor dos benefícios visa garantir aos segurado que o benefício será na exata proporção de suas contribuições.

Kertzman (2015, p. 55) trata do princípio da seletividade e distributividade dos benefícios e serviços, previsto no art. 194, parágrafo único, da Constituição Federal, de 1988, da seguinte forma:

\begin{abstract}
Seletividade na prestação dos benefícios e serviços implica que tais prestações sejam fornecidas apenas a quem realmente necessitar, desde que se enquadre nas situações que a lei definir. Somente poderão usufruir do auxílio-doença, por exemplo, os segurados que se encontrarem em situação de incapacidade temporária para o trabalho. Desta forma, o que realmente este princípio seleciona são os riscos sociais carecedores de proteção. Uma vez selecionado o risco, todas as pessoas que incorrerem na hipótese escolhida farão jus à proteção social. Em outra análise, a seletividade serve de contrapeso ao princípio da universalidade -da cobertura, pois, se de um lado a previdência precisa cobrir todos os riscos sociais existentes, por outro os recursos não são ilimitados, impondo à administração pública a seleção dos benefícios e serviços a serem prestados, com base na relevância dos riscos sociais. É o chamado princípio da reserva do possível.
\end{abstract}

O princípio da seletividade e distributividade dos benefícios e serviços implica na ideia de que o segurado realmente esteja em necessidade de contingência social para que possa usufruir do respectivo benefício ou serviço da previdência social. Não obstante, tais riscos são previstos em lei, de modo que o segurado deverá comprovar a existência dos requisitos exigidos. Outra questão apontada é a necessidade de equilíbrio entre a universalidade $\cdot$ da cobertura e a reserva do possível. Logo, para que esse equilíbrio seja garantido o sistema deve ter como vetor a relevância dos riscos sociais no momento da concessão dos benefícios.

Nesse contexto, destaca-se a relevância do princípio da legalidade no âmbito da previdência social. Isso porque, a legalidade vincula tanto os segurados, quando da concessão de benefício ser plenamente compatível com as exigências da lei, como também o Estado, que, conforme Ibrahim (2015, p. 63) afirma, "qualquer nova obrigação, como um aumento de contribuição, somente poderá ser feito por meio de lei em sentido formal, isto é, aprovada pelo Congresso Nacional ou, excepcionalmente, por medida provisória".

Portanto, entende-se que a previdência social, como parte da seguridade social, é tida como uma espécie de seguro, pelo qual os contribuintes, obrigatórios ou facultativos, podem usufruir de benefícios e serviços em momentos de contingência social. O sistema que baseia a previdência social é norteado por princípios, que devem ser considerados de maneira interativa, visando o equilíbrio do sistema ao mesmo tempo em que garante aos segurados não 
apenas gozarem dos benefícios oferecidos, mas também que esses sejam justos. Dentre os benefícios oferecidos, está o da aposentadoria, que é concedido nas regras que o determina. 
No entanto, questão relevante sobre esse benefício é a desaposentação. Logo, a próxima parte desta pesquisa tem por escopo o exame sobre o benefício da aposentadoria e o instituto da desaposentação.

\section{DO INSTITUTO DESAPOSENTAÇÃO}

A previdência social disponibiliza aos trabalhadores contribuintes diversos benefícios, dentre os quais se encontra o da aposentadoria. No entanto, na atualidade, um instituto vem ganhando pauta na esfera previdenciária e jurídica, a desaposentação.

De acordo com Kertzman (2015, p. 365) os benefícios previdenciários "são prestações pagas, em dinheiro, aos trabalhadores ou a seus dependentes”. Alguns desses benefícios vêm a substituir a remuneração do trabalhador, por algum motivo, está impedido de exercer a sua atividade laborativa, e assim, auferir renda, e, há outros benefícios que são oferecidos como complementação de rendimento do trabalho ou, ainda, independentemente do exercício da atividade.

Dentre os benefícios oferecidos pela previdência social encontra-se a aposentadoria. Hovarth Júnior (2011, p. 52) explica que “O vocábulo aposentadoria significa retirada a seus aposentos. Esse termo vem de retraite, retirement, retiro, taishoku, que são traduções de aposentadoria e indicam todas uma saída da força de trabalho". Desse modo, pode-se dizer que a aposentadoria é um benefício da previdência social que é disponibilizado aos segurados que não apresentam mais condições de continuar as atividades laborativas. Ou seja, a previdência social deve cobrir a contingência social que surge quando o segurado retira-se do mercado de trabalho de forma definitiva.

Nessa égide, Zarzana e Zarzana Júnior (2014, p. 34) afiançam que para se entender “a desaposentação, é preciso identificar claramente quem está aposentado legalmente, porque e em que situações". Assim sendo, é imprescindível esclarecer sobre as modalidades em que a aposentadoria se apresenta. Santos (2011), aponta as seguintes formas de aposentadoria: aposentadoria por invalidez, aposentadoria por idade, aposentadoria por tempo de contribuição e aposentadoria especial. Quanto à aposentadoria por invalidez, Ibrahim (2015, p. 591) esclarece:

\footnotetext{
A aposentadoria por invalidez é concedida ao segurado que, estando ou não em gozo de auxílio-doença, for considerado incapaz para o trabalho e insuscetível de reabilitação para o exercício de atividade que lhe garanta a subsistência, e ser-lhe-á paga enquanto permanecer nessa condição. O tema é tratado na Lei $n^{\circ}-8.213 / 91$, arts. 42 a 47, e no
} 
RPS, arts. 43 a 50. Assim, o fato de o segurado ter recebido anteriormente auxíliodoença é irrelevante. Todavia, na prática, a perícia médica concede o auxílio ao segurado, esperando que este venha a recuperar-se das lesões apresentadas. Caso isto não ocorra, chegando a perícia à conclusão de que o segurado é irrecuperável para a sua atividade ou inadaptável para outra, é então aposentado por invalidez.

A aposentadoria por invalidez é que se dá devido à incapacidade do trabalhador de modo a não ser possível a sua readaptação ou reabilitação, ainda que em outra atividade. Independentemente se antes da concessão dessa aposentadoria o segurado tiver usufruído de outro benefício previdenciário, o auxílio-doença, a aposentadoria por invalidez resguarda o contribuinte para o caso de invalidez total e permanente.

O valor desse benefício, cuja invalidez pode ou não ser decorrente de acidente do trabalho, corresponde a $100 \%$ do salário-de benefício do segurado, isto é, correspondente ao salário de contribuição, e pode ser acrescido de $25 \%$, nos casos em que "a invalidez o abrigue a necessitar de assistência permanente de outra pessoa. $\mathrm{O}$ acréscimo, entretanto, cessa com a morte do segurado, não sendo incorporável para efeito do cálculo de pensão", explica Santoro (2001, p. 69). Além disso, Vieira (2004, p. 391) assevera que o período de carência para a aposentadoria por invalidez é de doze contribuições mensais, ou doze meses para o segurado especial, porém, independe de carência "nos casos de acidente de qualquer natureza ou causa", ou pelo "acometimento de alguma das doenças ou afecções especificadas em lista elaborada pelos Ministérios da Saúde e da Previdência Social".

Acerca da aposentadoria por idade, Farineli (2013, p. 189) observa que o número mínimo de contribuições mensais, exigido para a sua concessão, é de 180, conforme dispõe o art. 25, da Lei $n^{\circ} 8.213 / 91$. Kravchychyn et. al (2014, p. 266) acrescenta:

\begin{abstract}
A aposentadoria por idade, criada pela Lei Orgânica da Previdência Social - Lei n. ${ }^{\circ}$ 3.807/1960 - e hoje mantida pela Lei n. $^{\circ} 8.213 / 1991$, é devida ao segurado que, cumprida a carência exigida, completar 65 anos de idade, se homem, ou 60 anos de idade, se mulher. Esses limites são reduzidos em cinco anos para os trabalhadores rurais de ambos os sexos e para os que exerçam suas atividades em regime de economia familiar, nestes inclusos o produtor rural, o garimpeiro e o pescador artesanal (art. 201, § 7. ${ }^{\circ}$, inciso II, da Constituição de 1988, com a redação da Emenda Constitucional n. $\left.{ }^{\circ} 20 / 1998\right)$
\end{abstract}

Ponderando os termos apresentados é possível afirmar que a aposentadoria por idade é que a se baseia na idade do trabalhador, e que pode ser concedida quando alcançados os limites de idade definidos em lei, bem como o número de contribuições mínimo exigido. Ademais, há determinadas categorias de trabalhadores que possui redução no limite de idade, de cinco anos, para a aposentadoria por idade, quais sejam, o garimpeiro, o pescador artesanal, e os que 
exerçam suas atividades em regime de economia familiar, abrangendo o produtor rural, em consonância com as determinações constitucionais vigentes 


\begin{abstract}
Em regra, o legislador constituinte reformador proibiu a adoção de requisitos diferenciados para a aposentadoria, salvo as atividades especiais prejudiciais à saúde ou integridade física do segurado, bem como no caso do trabalho prestado pelos portadores de deficiência física, em aplicação ao Princípio da Isonomia, pois se cuidam de situações diferenciadas que merecem um tratamento privilegiado. De efeito, no que concerne ao trabalho especial que prejudica a saúde e integridade física do trabalhador, o tema já era regulado pelos artigos 57 e 58, da Lei 8.213/91, que preveem o benefício da aposentadoria especial, tendo esses dispositivos normativos sido recebidos com força de lei complementar com o advento da Emenda 20/1998.
\end{abstract}

Essas considerações remetem ao entendimento de que para os contribuintes do sistema previdenciário não deve haver distinções ou privilégios. No entanto, por força do princípio da isonomia, ou seja, do princípio da igualdade, há situações em que a própria lei estabelece tratamento diferenciado, como no caso das pessoas com deficiência e a sua aposentadoria. Do mesmo modo, a aposentadoria especial é destinada aos trabalhadores que exerçam atividades prejudiciais à saúde ou integridade física. Com efeito, nessas conjecturas, é considerado que a aposentadoria especial se justifica, materializando o princípio da isonomia.

A aposentadoria especial, de acordo com Cruz (2003, p. 279) "depende de comprovação do tempo de trabalho permanente, não ocasional nem intermitente, durante quinze, vinte ou vinte e cinco anos em atividade" prejudicial à saúde ou à integridade física, observada a carência exigida que é de 180 contribuições mensais. No caso da aposentadoria especial das pessoas com deficiência, Kertzman (2015, p. 394) elucida que tal benefício se destina aos segurados que têm impedimentos de longo prazo, que podem ser de "natureza física, mental, intelectual ou sensorial, os quais, em interação com diversas barreiras, podem obstruir sua participação plena e efetiva na sociedade em igualdade de condições com as demais pessoas".

No que tange à aposentadoria por tempo de contribuição, Hovarth Júnior (2011, p. 52) a conceitua da seguinte forma:

Prestação previdenciária na modalidade beneficio devida aos segurados que completam os requisitos legais relativos a contributividade: 35 anos de contribuição, se homem, e trinta anos de contribuição, se mulher, independentemente da idade (para aposentadoria integral). Já para aposentadoria por tempo de contribuição proporcional, além do período contributivo (trinta anos de contribuição, se homem, e 25 anos de contribuição, se mulher), somam-se o requisito etário - 53 anos de idade (homens) e 48 anos de idade (mulheres) - e o tempo de contribuição adicional (pedágio) correspondente a $40 \%$ do tempo de serviço que faltava para a aposentadoria em 15 de dezembro de 1998 (data da promulgação da EC n. 20/98). 
À luz desses apontamentos, verifica-se que a aposentadoria por tempo de contribuição pode ser disponibilizada ao segurado quando completado o mínimo do tempo de contribuição exigido para que o benefício seja no valor integral respectivo. No entanto, é possível que esse número de contribuições seja reduzido, se levado em consideração a idade do segurado, contudo, com valor do benefício de forma proporcional.

Por outro lado, uma significativa inovação jurídica passou a redefinir a aposentadoria por tempo de contribuição. Com o advento da Lei $\mathrm{n}^{\circ} 13.183$, de 04 de novembro de 2015, a aposentadoria por tempo de contribuição, apesar de estar disponível a partir do momento em que preenchidos os requisitos legais, pode ou não exigir a incidência do fator previdenciário, conforme agora dispõe o art. 29-C, da Lei ${ }^{\circ} 8.213 / 91$. O $\S 1^{\text {o }}$, desse novo dispositivo legal, preceitua que os fatores que envolvem essa questão são a idade, o tempo de contribuição e se o segurado for homem ou mulher.

Não obstante, no que se refere à aposentadoria por tempo de contribuição, Martinez (2014, p. 877) explana:

\begin{abstract}
A prestação mais polêmica da legislação previdenciária e a mais desejada pelos brasileiros é a aposentadoria por tempo de contribuição. Originária do serviço público, denominada como sendo ordinária na Lei Eloy Marcondes de Miranda Chaves, provocou discussões e dissenções no ambiente político, científico e técnico nos anos 1992/1998, e até hoje, estando possivelmente condenada ao desaparecimento em razão de suas distorções (v.g., falta de fonte específica, ausência de limite etário pessoal, frequente volta ao trabalho, dúvida sobre a existência de risco, acumulação com outros benefícios, adoção de regime de repartição simples, fator previdenciário etc.). [...] Tratase benefício substituidor do salário, de pagamento continuado, definitivo e não reeditável, na modalidade integral devido aos segurados, mulher com 30 anos e homem com 35 anos de contribuição.
\end{abstract}

Nota-se que a aposentadoria por tempo de contribuição é o benefício que envolve maior polêmica e discussão. Inclusive tal juízo se forma a partir de fatores como a frequente volta ao trabalho dos segurados que já usufruem desse benefício.

Nesse cenário, Zarzana e Zarzana Júnior (2014, p. 04) conceituam a desaposentação como a "renúncia do benefício original de aposentadoria que um segurado recebe, para que, em ato contínuo, ele possa receber aposentadoria mais vantajosa", sem a necessidade de devolver os valores recebidos com a primeira aposentadoria. Santos $(2011$, p. 325) assevera que a lei não prevê a possibilidade de incidência da desaposentação, razão pela qual somente é concedida quando levada a questão ao judiciário. Além disso, essa autora apresenta a seguinte concepção ao 
instituto: "Desaposentação é, então, a desconstituição do ato de concessão da aposentadoria, que depende da manifestação de vontade do segurado". 
Com fundamento na legislação vigente, Santos (2011, p. 324-325) explica:

\begin{abstract}
As constantes modificações da legislação previdenciária, notadamente com relação à proibição de acumulação de aposentadorias dentro do mesmo regime previdenciário, bem como os reduzidos valores da renda mensal desses benefícios, fizeram surgir uma nova pretensão: a desaposentação. Não raro, o aposentado continua a trabalhar e participar do custeio do regime previdenciário, embora sem direito à nenhuma cobertura em razão dessa nova filiação (art. $18, \S 2^{\circ}$, do PBPS). Acresce ao reduzido valor de sua aposentadoria o da remuneração pela atividade que passa a exercer, e continua a pagar contribuição previdenciária incidente sobre esse valor (novo salário de contribuição). Com o passar do tempo, acaba concluindo que não pode mais trabalhar e, como não tem direito à cobertura previdenciária em razão da atividade que passou a exercer, arca com a perda desses rendimentos. Surge, então, a pretensão de desistir da aposentadoria que já recebe para acrescer o tempo de contribuição decorrente da nova atividade ao que já lhe dera direito à aposentação, e, assim, obter nova aposentadoria, desta vez com renda mensal de valor maior.
\end{abstract}

A análise das lições leva ao entendimento de que a legislação previdenciária impede o acúmulo de aposentadorias, e, somado ao fato de que os valores que compõem esses benefícios nem sempre são satisfatórios ao segurado, por vezes, o mesmo, ainda que aposentado, continua a trabalhar. Consequentemente, o já aposentado ainda continua também a contribuir com o sistema sob a remuneração da atividade laborativa que exerce, porém, sem a possibilidade de usufruir de novos benefícios ou coberturas. É nessa órbita que surge a questão da desaposentação.

Amado (2015, p. 868) assevera, considerando o art. 11, § 3º da Lei $n^{\circ} 8.213 / 91$, que “o aposentado que desenvolver atividade remunerada será filiado obrigatório no que concerne a essa atividade, devendo pagar as respectivas contribuições previdenciárias”. Ou seja, o aposentado que decide por voltar às atividades laborativas remuneradas não possui a hipótese de não contribuir com a previdência social, a lei o obriga a isso sem que exista qualquer possibilidade de um retorno, a não ser a aposentadoria que já usufrui.

Nesse contexto, Kertzman (2015, p. 473) observa:

As aposentadorias por idade, tempo de contribuição e especial concedidas pela Previdência Social são irreversíveis e irrenunciáveis. O segurado pode, contudo, desistir do pedido de aposentadoria, desde que manifeste essa intenção e requeira o arquivamento definitivo do pedido antes do recebimento do primeiro pagamento do benefício, ou de sacar o respectivo FGTS ou PIS, ou até 30 dias da data do processamento do benefício, prevalecendo o que ocorrer primeiro. Ressaltamos, no entanto, que a tese da desaposentação, que permite ao segurado renunciar à sua aposentadoria para alcançar um benefício mais vantajoso, vem sendo cada vez mais aceita pela jurisprudência. A desaposentação pode ser vantajosa em diversas situações. 
Compreende-se que, assim como na aposentadoria por tempo de contribuição, como nas aposentadorias por idade e especial, há a possibilidade de desistência do pedido do benefício junto à previdência social antes do recebimento do primeiro benefício, ou saque do 
FGTS ou PIS, ou ainda, antes de 30 dias do processamento do benefício. Contudo, outra possibilidade tem sido cogitada e aceita pela jurisprudência, qual seja a desaposentação, que não se limita aos critérios de desistência assinalados.

Farineli (2013, p.1052) assegura que a "possibilidade do segurado renunciar ao seu direito disponível, chamado aposentadoria, é aceito tanto pelos Tribunais quanto pela doutrina". Em consonância a isso, ressalta-se a ementa do julgamento, pelo Superior Tribunal de Justiça, do Recurso Especial no 1.334.488 - SC (2012/0146387-1):

\begin{abstract}
RECURSO ESPECIAL. MATÉRIA REPETITIVA. ART. 543-C DO CPC E RESOLUÇAO STJ 8/2008. RECURSO REPRESENTATIVO DE CONTROVÉRSIA. DESAPOSENTAÇAO E REAPOSENTAÇAO. RENÚNCIA A APOSENTADORIA. CONCESSAO DE NOVO E POSTERIOR JUBILAMENTO. DEVOLUÇAO DE VALORES. DESNECESSIDADE. 1. Trata-se de Recursos Especiais com intuito, por parte do INSS, de declarar impossibilidade de renúncia a aposentadoria e, por parte do segurado, de dispensa de devolução de valores recebidos de aposentadoria a que pretende abdicar. 2. A pretensão do segurado consiste em renunciar à aposentadoria concedida para computar período contributivo utilizado, conjuntamente com os salários de contribuição da atividade em que permaneceu trabalhando, para a concessão de posterior e nova aposentação. 3. Os benefícios previdenciários são direitos patrimoniais disponíveis e, portanto, suscetíveis de desistência pelos seus titulares, prescindindo-se da devolução dos valores recebidos da aposentadoria a que o segurado deseja preterir para a concessão de novo e posterior jubilamento. Precedentes do STJ. [...] 6. Recurso Especial do INSS não provido, e Recurso Especial do segurado provido. Acórdão submetido ao regime do art. 543-C do CPC e da Resolução 8/2008 do STJ. (BRASIL, 2016, online). (grifo nosso).
\end{abstract}

Observa-se pelo juízo do Superior Tribunal de Justiça nesse caso é de que a renúncia da aposentadoria pelo segurado é possível, pois se trata de direito patrimonial disponível. Nessa situação, o INSS busca, por meio do Recurso Especial, a impossibilidade da renúncia da aposentadoria do segurado, enquanto o segurado requer a não devolução dos valores recebidos. Assim, a referida Corte decidiu pelo não provimento ao INSS, e proferiu a favor do segurado. Isto é, entendeu que existe a possibilidade de renúncia do benefício, bem como não há necessidade de devolução dos valores recebidos por essa aposentadoria renunciada.

Por outro lado, a Advocacia-Geral da União, que representa o INSS, requereu ao Supremo Tribunal Federal a suspensão de todos os processos de desaposentação que tramitam no país, por meio de petição no âmbito do Recurso Extraordinário no 661.256. Com amparo no novo Código de Processo Civil, alertando "para o impacto financeiro da matéria para os cofres da Previdência Social, que pode chegar a R\$ 181,8 bilhões nos próximos 30 anos”, conforme notícias divulgadas no site da própria Advocacia-Geral da União. O referido Recurso 
Extraordinário no 661.256 se encontra em tramitação, e seu relator é o Ministro Roberto Barroso, que em seu voto, juntado em 09/10/2014, reconhece a inexistência de lei 
específica a tratar da desaposentação. Nesse voto, alguns pontos se destacam como o de que na diante da existência de lei, o critério a ser adotado pelo Judiciário nesses casos considera no cálculo dos novos proventos, os fatores idade e expectativa de vida devem ser aferidos com referência ao momento de aquisição da primeira aposentadoria.

Não obstante, o relator Ministro Roberto Barroso demonstra entendimento em seu voto de que "os aposentados em atividade contribuem em igualdade de condições e têm acesso a benefícios inexistentes ou extremamente limitados". Ou seja, os aposentados que retomam a atividade possuem igualdade de condições com relação aos outros contribuintes no que se refere aos deveres, especialmente no que tange à obrigatoriedade de contribuição. Por outro lado, não há a mesma isonomia quanto ao exercício de direitos, pois com o fato da primeira aposentadoria, o segurado não pode mais usufruir de nenhum outro benefício, e, sem a desaposentação, apenas ficam os deveres e a desproporcionalidade do que realmente contribuiu e o que recebe. Assim, para esse Ministro, o cálculo da nova aposentadoria deve considerar a idade e a expectativa de vida como as referentes ao momento em que a primeira aposentadoria foi estabelecida, e não a segunda.

\section{CONSIDERAÇÕES FINAIS}

A seguridade social se apresenta como um sistema protetivo dos membros da sociedade, ensejando a participação tanto dos particulares como do Estado para o seu funcionamento e manutenção. Assim, a seguridade social é um sistema financiado pelo Estado e pela sociedade a fim de assegurar prestações de serviços e benefícios em momentos de contingência social, visando assegurar o bem-estar dos indivíduos e a justiça social, por meio de um atendimento igualitário. Ademais, a seguridade social abrange as vertentes da saúde, da assistência social e da previdência social.

No âmbito da previdência social, os benefícios e serviços são disponibilizados apenas aos segurados contribuintes, diferentemente da saúde e da assistência social. Cuida-se de um mecanismo, o qual depende do financiamento pelo Estado, empregadores e trabalhadores, que disponibiliza prestações, na esfera dos direitos sociais, aos seus segurados e dependentes em situações em que não é possível auferir renda para a subsistência, por meio das atividades laborativas. 
Dentre os benefícios da previdência social se encontra a aposentadoria, que é disponibilizada aos trabalhadores, preenchidos os requisitos legais, nas modalidades: aposentadoria por idade, por invalidez, especial e por tempo de contribuição. Diante disso, foi feita uma breve análise dos tipos de aposentadoria, na terceira parte da pesquisa, para se adentrar na questão da desaposentação. Assim, percebeu-se que a aposentadoria é o benefício que o trabalhador contribuinte, ou seja, o segurado, pode usufruir em de determinado momento de sua vida em que deixa de fazer parte do mercado de trabalho, desde que alcançados os critérios legais. A desaposentação, por outro lado, é a renúncia da aposentadoria, de modo que o aposentado, por qualquer razão, continua no mercado de trabalho, e consequentemente, continua contribuindo com a previdência social, para que uma nova aposentadoria seja concedida de forma mais vantajosa.

Constatou-se que o ordenamento jurídico não tem previsão sobre a possibilidade de desaposentação, motivo pelo qual muitos casos têm chegado ao Judiciário. Este, por sua vez, tem entendido a desaposentação como algo viável, inclusive sem a devolução dos valores recebidos do primeiro benefício.

Dessa forma, foi possível entender que a desaposentação é um direito do trabalhador segurado. Contudo, para que se evite oneração excessiva da previdência social, o cálculo do segundo benefício da aposentadoria deve ser pautado em critérios que a lei ainda não prevê, mas que têm sido apontados pela jurisprudência como forma de resguardar o direito desse trabalhador, mas sem trazer custo excessivo.

\section{REFERÊNCIAS}

AMADO, Frederico. Direito Previdenciário. 5. ed., rev., ampl. e atual. Salvador: JusPODIVM, 2015.

ARAUJO, Luiz Alberto David; NUNES JÚNIOR, Vidal Serrano. Curso de Direito Constitucional. 18. ed. rev. e atual. até a EC 76 de 28 de novembro de 2013. São Paulo: Editora Verbatim, 2014.

BONAVIDES, Paulo. Curso de Direito Constitucional. 28. ed., atual. (em apêndice texto da Constituição Federal de 1988, com as Emendas Constitucionais até a de nº 71, de 29.11.2012). São Paulo: Malheiros, 2013.

BRASIL. Advocacia-Geral da União. Desaposentação: AGU Estima Impacto de R\$ 181 bi e Pede ao STF Suspensão de Ações. Publicado : 13/04/2016-Alterado : 19/04/2016. In: Advocacia-Geral da União: Notícias: 
$1988 . \quad$ Disponível em:

Constituição Federal da República Federativa do Brasil, de 05 de Outubro de <http://www.planalto.gov.br/ccivil_03/constituicao/ConstituicaoCompilado.htm>. Acesso em 28 de Março de 2016.

Lei $n^{0}$ 8.213, de 24 de Julho de 1991. Dispõe sobre os Planos de Benefícios da Previdência Social e dá outras providências. Disponível em: <http://www.planalto.gov.br/ccivil_03/LEIS/L8213cons.htm>. Acesso em 30 de Março de 2016.

Lei $\mathrm{n}^{\mathbf{0}}$ 13.183, de 04 de Novembro de 2015. Altera as Leis $\mathrm{n}^{\mathrm{oS}} 8.212$, de 24 de julho de 1991, e 8.213, de

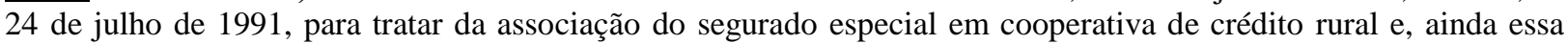
última, para atualizar o rol de dependentes, estabelecer regra de não incidência do fator previdenciário, regras de pensão por morte e de empréstimo consignado, a Lei no 10.779, de 25 de novembro de 2003, para assegurar pagamento do seguro-defeso para familiar que exerça atividade de apoio à pesca, a Lei $\mathrm{n}^{\circ} 12.618$, de 30 de abril de 2012, para estabelecer regra de inscrição no regime de previdência complementar dos servidores públicos federais titulares de cargo efetivo, a Lei $\mathrm{n}^{\circ} 10.820$, de 17 de dezembro de 2003, para dispor sobre o pagamento de empréstimos realizados por participantes e assistidos com entidades fechadas e abertas de previdência complementar e a Lei $\mathrm{n}^{\circ}$ 7.998, de 11 de janeiro de 1990; e dá outras providências. Disponível em: <http://www.planalto.gov.br/ccivil_03/_Ato2015-2018/2015/Lei/L13183.htm>. Acesso em 10 de Junho de 2016.

Superior Tribunal de Justiça. Recurso Especial no 1.334.488 - SC (2012/0146387-1). RELATOR: MINISTRO HERMAN BENJAMIN. RECORRENTE: WALDIR OSSEMER. ADVOGADO: CARLOS BERKENBROCK E OUTRO (S). RECORRENTE: INSTITUTO NACIONAL DO SEGURO SOCIAL - INSS. ADVOGADO: PROCURADORIA-GERAL FEDERAL - PGF. RECORRIDO: OS MESMOS. INTERES.: CONFEDERAÇAO BRASILEIRA DOS APOSENTADOS PENSIONISTAS E IDOSOS COBAP - "AMICUS CURIAE". ADVOGADO: JOSÉ IDEMAR RIBEIRO. Brasília, 08 de maio de 2013 (data do julgamento). Disponível em: <http://stj.jusbrasil.com.br/jurisprudencia/23214413/recurso- especial-resp-1334488-sc-2012-0146387-1stj/inteiro-teor-23214414>. Acesso em 10 de Junho de 2016.

Supremo Tribunal Federal. Recurso Extraordinário $\mathbf{n}^{\mathbf{0}}$ 661.256. RELATOR: MINISTRO ROBERTO BARROSO. RECTE.(S) - INSTITUTO NACIONAL DO SEGURO SOCIAL - INSS. PROC.(A/S)(ES) PROCURADOR-GERAL FEDERAL. RECDO.(A/S) - VALDEMAR RONCAGLIO. ADV.(A/S) - ADILSON VIEIRA MACABU. AM. CURIAE. - INSTITUTO BRASILEIRO DE DIREITO PREVIDENCIÁRIO- IBDP. ADV.(A/S) - GISELE LEMOS KRAVCHYCHYN. AM. CURIAE. - UNIÃO. PROC.(A/S)(ES) - ADVOGADOGERAL DA UNIAO. AM. CURIAE. - CONFEDERAÇÃO BRASILEIRA DE APOSENTADOS E PENSIONISTAS - COBAP. ADV.(A/S) - GABRIEL DORNELLES MARCOLIN. Em andamento. Disponível em:

<http://www.stf.jus.br/portal/jurisprudenciarepercussao/verAndamentoProcesso.asp?incidente $=4157562 \&$ numeroProcesso $=661256 \&$ classeProcesso=RE\&numeroTema $=503 \#>$. Acesso em 08 de Junho de 2016.

CARVALHO, Kildare Gonçalves. Direito Constitucional: Teoria do Estado e da Constituição; Direito Constitucional Positivo. 19. ed., rev. atual. e ampl. Belo Horizonte: Del Rey, 2012.

CASTRO, Carlos Alberto Pereira de; LAZZARI, João Batista. Manual de Direito

Previdenciário. 12 ed., rev. e atual. Conforme a legislação em vigor até janeiro de 20 
CRUZ, Alexsandro C. Direito e Legislação Previdenciária: Custeio e Benefícios. Petrópolis: ParkGraf, 2003.

DIAS, Eduardo Rocha; MACÊDO, José Leandro Monteiro de. Curso de Direito

Previdenciário. 2. ed., rev. e atual.. Rio de Janeiro: Forense; São Paulo: Método, 2010.

FARINELI, Alessandro Menezes. Prática Processual Previdenciária. 7. ed. Leme/São

Paulo: Mundo Jurídico, 2013.

HORVATH Junior, Miguel. Direito Previdenciário. Barueri, SP: Manole, 2011.

IBRAHIM, Fábio Zambitte. Curso de Direito Previdenciário. 3 ed., rev., ampl. e atual. Rio de Janeiro; Impetus, 2003.

Curso de Direito Previdenciário. 20. ed., rev. e atual. Rio de Janeiro: Impetus, 2015. KERTZMAN, Ivan. Curso de Direito Previdenciário. 12. ed., rev., ampl. e atual. Salvador: JusPODIVM, 2015.

KRAVCHYNCHY, Jefferson Luis; KRAVCHYNCHY, Gisele Lemos; CASTRO, Carlos Alberto Pereira de; LAZZARI, João Batista. Prática Processual Previdenciária: Administrativa e Judicial. 5. ed., rev., atual. e ampl. Rio de Janeiro: Forense, 2014.

MARTINEZ, Wladimir Novaes. Curso de Direito Previdenciário. 6. ed. São Paulo: LTr, 2014.

SANTORO, José Jayme de Souza. Manual de Direito Previdenciário. 2. ed. Rio de Janeiro: Freitas Bastos Editora, 2001.

SANTOS, Marisa Ferreira dos. Direito Previdenciário Esquematizado. Organizador: LENZA, Pedro. São Paulo: Saraiva, 2011.

SILVA, José Afonso da. Curso de Direito Constitucional Positivo. 36 ed., rev. e atual. (até a Emenda Constitucional nº 71, de 29.11.2012). São Paulo: Malheiros, 2013.

VIANNA, Cláudia Salles Vilela. Previdência Social: Custeio e Benefícios. 2. ed. São Paulo: LTr, 2008.

VIEIRA, Marco André Ramos. Manual de Direito Previdenciário: Teoria, Jurisprudência e 520 Questões. 4 ed., rev., ampl. e atual. até a EC nº 44/2004. Rio de Janeiro: Impetus, 2004.

ZARZANA, Dávio Antonio Prado; ZARZANA JÚNIOR, Dávio Antonio Prado. Desaposentação: Passo a Passo. Rio de Janeiro: Elieser, 2014. 